\title{
Modelling of Instant Solar Radiation Using Average Instant Temperature of Ogbomoso, South Western, Nigeria
}

\author{
Oluwaseun Adedokun*, Aishat Abidemi Abass, Yekinni Kolawole Sanusi \\ Department of Pure and Applied Physics, Ladoke Akintola University of Technology, P.M.B. 4000, Ogbomoso, Nigeria \\ (oadedokun@lautech.edu.ng, abass.aishat36@yahoo.com, yksanusi@lautech.edu.ng)

\begin{abstract}
*Corresponding Author: Oluwaseun Adedokun, Department of Pure and Applied Physics, Ladoke Akintola University of Technology, P.M.B. 4000, Ogbomoso, Tel: +234 7031195750, oadedokun@lautech.edu.ng
\end{abstract}

\begin{abstract}
The paper is aimed at proffering an alternative means to the meteorological measuring stations by generating models for average instant solar radiation as a function of instant average temperature at places where measurement are not available. The data were processed using Microsoft excel software programming and regression analysis to generate a set of models for both morning and afternoon sessions of instant solar radiation of Ogbomoso as a function of temperature. In order to validate these models, statistical indicators like RMSE, MBE and MPE were used. The value of RMSE, MBE and MPE statistical indicators for morning and afternoon set of data were calculated to be $0.001219,-0.0000002,0.0059 \%$ and $0.00033769,-0.00171225,-4.82 \%$, respectively. From the t-test statics, percentage error between the measured and calculated values of instant average temperature, it is revealed that the set of models in this work can adequately be used in place of the data from the measuring stations since there is complementary relationship between the measured and the calculated instant solar radiation of Ogbomoso. And this modelling result could be used in the estimation of instant solar radiation at locations where measurements are not available to design high performance solar radiation related devices.
\end{abstract}

Keywords: Instant solar radiation, average instant temperature, modelling, statistical indicators, Nigeria

\section{Introduction}

Energy is the motive force behind the continual technological improvement of any nation and Nigeria is blessed with reasonably high quantities of various energy resources [1]. The time needed to develop a new source of energy, such as solar energy, can be provided through the conservation of energy resources. Solar radiation passing through the atmosphere to the ground surface is known to be depleted through scattering, reflection and absorption by the atmospheric constituents like air molecules, aerosols, water vapour, ozone and the clouds. In any conversion of solar energy, the understanding of global solar radiation is essential in achieving a quality design and the expectation of the system performance. Practically, solar radiation data is the most important parameter in the design and evaluation of solar energy devices. An accurate knowledge of solar radiation distribution at a particular geographical location is of vital importance for surveys in agronomy, hydrology, eulogy and sizing of the photovoltaic or thermal solar systems and estimates of their performance. To collect the solar radiation data, a system of solar maintaining station fitted out with pyranometer and data gain system are generally founded in the desired locations which is used by researchers to extrapolate values for places of similar climatological and geographical characteristics at which solar records are unavailable. A Few numbers of such stations are in Nigeria and insufficient to present reports of solar radiation on desired locations especially in developing countries. This is due to their inability to afford the measuring equipment and lack of maintenance and calibration of the equipment. In other to solve this problem an approach is used here to model an equation to estimate instant solar radiation as a function of instant average temperature to be used in places where measurement are not available. Instant temperature is easy to measure using digital thermometer which is affordable. Another approach is comparing the global solar radiation to climatological data at the location where the data is collated. The first empirical correlation using sunshine hours for estimation of solar radiation was proposed by Angstrom [2]. This model was later modified by Prescott and Page [2- 4] in which the model is given as:

$\frac{H}{H o}=\mathrm{a}+\mathrm{b} \frac{S}{S o}$ 
Where $\mathrm{H}$ is the monthly average daily global radiation on horizontal surface, Ho is the monthly average daily extraterrestrial radiation, $S$ is the length of the day, So is the maximum possible sunshine duration, and $\mathrm{a}$ and $\mathrm{b}$ are constants. Since this development, there have been other models such as Rietveld, Bahel, Glover, Hay and Grag models [5]. Akpabio et al. [6] developed the quadratic form of Angstrom-Prescott model and used it to estimate the global solar radiation at Onne, Nigeria (latitude $4^{\circ} 46^{\prime} \mathrm{N}$, Longitude $7^{\circ} 10^{\prime}$ E). Multi-linear polynomial form of the AngstromPrescott model was employed by Agbo et al. [7] to estimate global solar radiation at Minna, Nigeria. Various other models employing other meteorological parameters with one or more variables with solar radiation have also been used. The estimation of the solar radiation at Uturu in Nigeria was carried out using an equation relating solar radiation and temperature [8]. Agbo [9] had also estimated 'global' solar radiation at Onitsha using regression analysis and artificial neural network models with the attendant parameters of temperatures and relative humidity. Here in this work, models were formulated using a simple method and statistical indicators such as (RMSE, MPE, MSE, $r$ and $r^{2}$ ), curve tracing, t-test statistics, were used to validate the models estimated.

\section{Materials and Methods}

The monthly mean daily data for maximum ambient temperature and the solar radiation data for Ogbomosho were collected from the Archives of the Nigerian Meteorological Agency (NIMET), Lagos, Nigeria. The data obtained covered a period of a year for Ogbomoso at Latitude $8.3^{\circ}$ and Longitude $4.3^{\circ}$. The data obtained were processed to hourly average in preparation for the correlation between instant solar radiation and instant average temperature.

Some given temperature comprises of two values, so we cannot get the solar radiation as a single valued function of temperature for these data. In other to obtain radiation as the function of temperature, we use Excel software program to break down the data at the turning point and get relation of instant solar radiation with instant temperature for morning hours and evening hours separately. Percentage errors will be estimated between the values obtained from the Metrological centre and the values predicted by the developed equation.

\subsection{The comparison methods}

In this study, evaluation of the accuracy of estimated data from the above described models is done using the following statistical tests, MBE, RMSE, mean percentage error (MPE) and coefficient of correlation ( $r$ ). Correlation between predicted and measured values is tested using Curve tracing process.

\subsection{The root mean square error, mean bias error and mean percentage error}

The Root Mean Square Error (RMSE) (also called the root mean square deviation, RMSD) is a frequently used measure of the difference between values predicted by a model and the values actually observed from the environment that is being modelled. These individual differences are also called residuals, and the RMSE serves to aggregate them into a single measure of predictive power. The accuracy of the estimate depends on the lower value of RMSE. However, an increase in RMSE can be caused by a few large errors in the sum. Obviously, every single test may not be a suitable indicator of a pyranometer's performance. It is possible to have a large RMSE value and simultaneously a small MBE (a large scatter about the line of perfect measurement) or possibly vice-versa i.e a small RMSE and large MBE (consistently small over- or under measurement). Although these statistical indictors generally gives a reliable procedure to compare models, but do not accurately indicate whether a model's measures are statistically significant, that is, not significantly different from their predicted counterparts. In this article, t-statistic was used as an additional statistical indicator. This statistical indicator enables models to simultaneously compare and indicates whether or not a model's measures are statistically valid at a particular reliable level [10]. It was seen that the t-statistic used in addition to the RMSE and MBE gave more reliable and explanatory results [11].

$\operatorname{RMSE}=\left\{\sum_{i=1}^{n}\left(\frac{K_{T P}-K_{T M}}{n}\right)^{2}\right\}^{1 / 2}$

A positive value of mean bias error (MBE) shows an overestimate while a negative value an under-estimate by the model and the lower the value for a particular model, the better the performance. This test gives information on the long-term performance

$\mathrm{MBE}=\frac{\left\{\sum_{i=1}^{n}\left(K_{T P}-K_{T M}\right)\right\}}{n}$

The mean percentage error (MPE) gives long term performance of the examined regression equations, a positive MPE values provides the averages amount of overestimation in the calculated values, while the negatives value gives underestimation. A low value of MPE is desirable [12].

$M P E=\left\{\sum_{i=1}^{n}\left(\frac{K_{T P}-K_{T M}}{\frac{K T M}{n}}\right)\right\} \times 100$

Where $\mathrm{K}_{\mathrm{TP}}$ is the predicted value $\mathrm{K}_{\mathrm{TM}}$ is the measured values and $\mathrm{n}$ is the total number of observations.

\section{The t-Statistics Test}

In one of the tests for mean values as defined by a student [13], the random variable $t$ with $n-1$ degrees of freedom may be written as follows:

$\mathrm{t}=\sqrt{ }\left[\frac{(n-1)(M B E)^{2}}{(R M S E)^{2}-(M B E)^{2}}\right]$

The smaller the value of $t$, the better is the performance. To determine whether a model's estimates are statistically significant, one simply has to determine, from standard statistical tables, the critical $t$ value, i.e. $t \alpha / 2$ at $\alpha$ level of significance and $(n-1)$ degrees of freedom. For the model's estimates to be judged statistically significant at the $(1-\alpha)$ confidence level, the calculated t value must be less than the critical value. 


\section{Results and Discussion}

Figure 1 shows a plot of instant solar radiation and instant average temperature for the year 2012. It is obvious that extraction of data here may be difficult. Therefore, in other to simplify the process, the data were grouped as mentioned in previous section. From Table 1, there are two values for some given temperature. So it is difficult to get solar radiation as a single valued function of temperature for these data. In other to get the radiation as the function of temperature, we then break the data at the turning point and get relation of instant solar radiation with instant temperature for morning hours and evening hours separately by using Microsoft Excel.

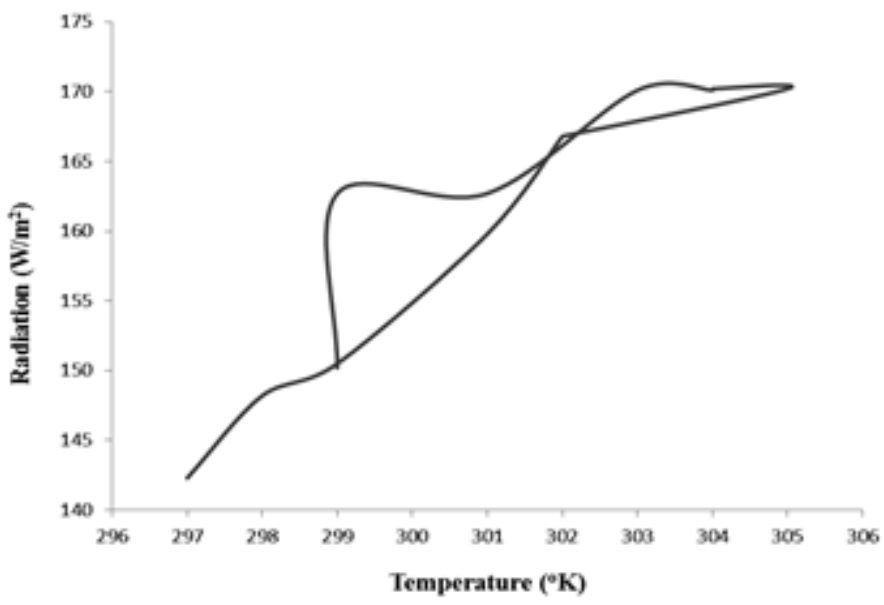

Fig. 1. Instant solar radiation against instant average temperature for the year 2012

Table 1. Instant average temperature and instant solar radiation of Ogbomoso from January 2012 to December 2012

\begin{tabular}{cccc}
\hline $\begin{array}{c}\text { Time } \\
(\mathbf{h r})\end{array}$ & $\begin{array}{c}\text { Instant Solar } \\
\text { Radiation } \\
\left(\mathbf{W m}^{-2}\right)\end{array}$ & $\begin{array}{c}\text { Instant } \\
\text { Temperature } \\
\left({ }^{\mathbf{0}} \mathbf{C}\right)\end{array}$ & $\begin{array}{c}\text { Instant } \\
\text { Temperature } \\
\left({ }^{\mathbf{0}} \mathbf{K}\right)\end{array}$ \\
\hline 7:00 am & 142.30 & 24 & 297 \\
8:00 am & 148.20 & 25 & 298 \\
9:00 am & 150.50 & 26 & 299 \\
10:00am & 159.80 & 28 & 301 \\
11:00 am & 166.80 & 29 & 302 \\
12:00 pm & 166.80 & 30 & 303 \\
1:00 pm & 170.20 & 32 & 305 \\
2:00 pm & 170.20 & 31 & 304 \\
3:00 pm & 170.10 & 31 & 304 \\
4:00 pm & 170.10 & 30 & 303 \\
5:00 pm & 162.70 & 28 & 301 \\
6:00 pm & 162.70 & 26 & 299 \\
7:00 pm & 150.20 & 26 & 299 \\
\hline
\end{tabular}

The relation between the instant solar radiation and instant temperature is to be developed for morning data where 7.00 $\mathrm{AM}$ to $11.00 \mathrm{AM}$ were taken. And the relation between the instant solar radiation and instant temperature is to be developed for afternoon data where $12.00 \mathrm{PM}$ to $7.00 \mathrm{PM}$ were taken. The data were shown as in the given Table 2 and 3, respectively.

Table 2. Showing reports for morning hours on an instant solar radiation and instant average temperature

\begin{tabular}{cccc}
\hline $\begin{array}{c}\text { Time } \\
(\mathbf{h r})\end{array}$ & $\begin{array}{c}\text { Instant Solar } \\
\text { Radiation } \\
\left(\mathbf{W m}^{-\mathbf{2}}\right)\end{array}$ & $\begin{array}{c}\text { Instant } \\
\text { Temperature } \\
\left({ }^{\mathbf{}} \mathbf{C}\right)\end{array}$ & $\begin{array}{c}\text { Instant } \\
\text { Temperature } \\
\left({ }^{\mathbf{0}} \mathbf{K}\right)\end{array}$ \\
\hline 7:00 am & 142.30 & 24 & 297 \\
8:00 am & 148.20 & 25 & 298 \\
9:00 am & 150.50 & 26 & 299 \\
10:00am & 159.80 & 28 & 301 \\
11:00 am & 166.80 & 29 & 302 \\
\hline
\end{tabular}

Table 3. Showing reports for afternoon hours on an instant solar radiation and instant average temperature

\begin{tabular}{cccc}
\hline $\begin{array}{c}\text { Time } \\
(\mathbf{h r})\end{array}$ & $\begin{array}{c}\text { Instant Solar } \\
\text { Radiation } \\
\left(\mathbf{W m}^{-\mathbf{2}}\right)\end{array}$ & $\begin{array}{c}\text { Instant } \\
\text { Temperature } \\
\left({ }^{\mathbf{O}} \mathbf{C}\right)\end{array}$ & $\begin{array}{c}\text { Instant } \\
\text { Temperature } \\
\left({ }^{\mathbf{0}} \mathbf{K}\right)\end{array}$ \\
\hline 12:00 pm & 166.80 & 30 & 303 \\
$1: 00 \mathrm{pm}$ & 170.20 & 32 & 305 \\
$2: 00 \mathrm{pm}$ & 170.20 & 31 & 304 \\
$3: 00 \mathrm{pm}$ & 170.10 & 31 & 304 \\
$4: 00 \mathrm{pm}$ & 170.10 & 30 & 303 \\
$5: 00 \mathrm{pm}$ & 162.70 & 28 & 301 \\
$6: 00 \mathrm{pm}$ & 162.70 & 26 & 299 \\
7:00 pm & 150.10 & 26 & 299 \\
\hline
\end{tabular}

The estimated equation from the graph in Figure 2 is obtained using Microsoft excel software as expressed in Equation 6, where the solar radiation $\left(\mathrm{W} / \mathrm{m}^{2}\right)$ is plotted against the instant average temperature $\left({ }^{\circ} \mathrm{K}\right)$ for the morning section from the hour of 7:00 AM to 11:00 AM. The equation has a dependent variable (solar radiation) and an independent variable (temperature) represented as $\mathrm{R}$ and $\mathrm{T}$, respectively.

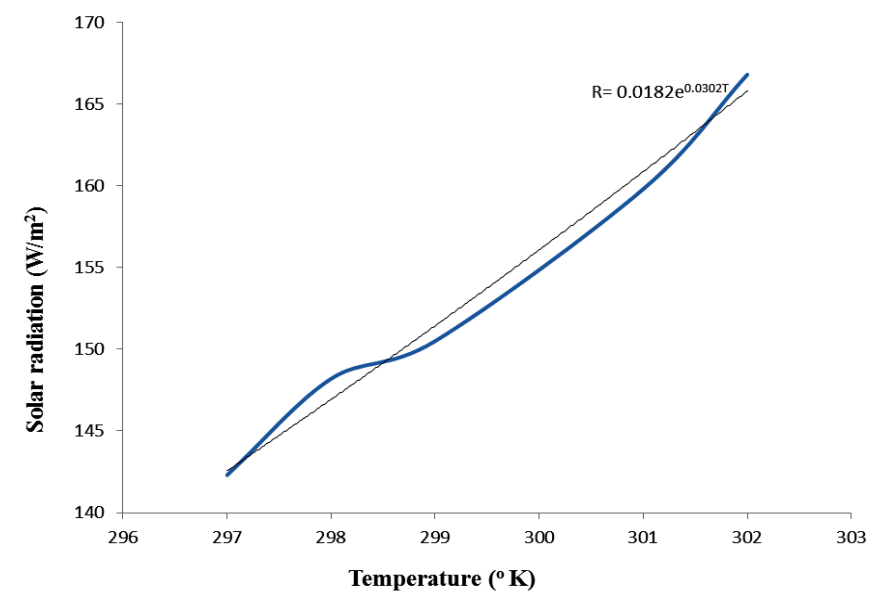

Fig. 2. Showing records for the morning on variation in instant solar radiation and instant temperature 
INTERNATIONAL JOURNAL Of ENGINEERING TECHNOLOGIES

Oluwaseun Adedokun et al., Vol.1, No.3, 2015

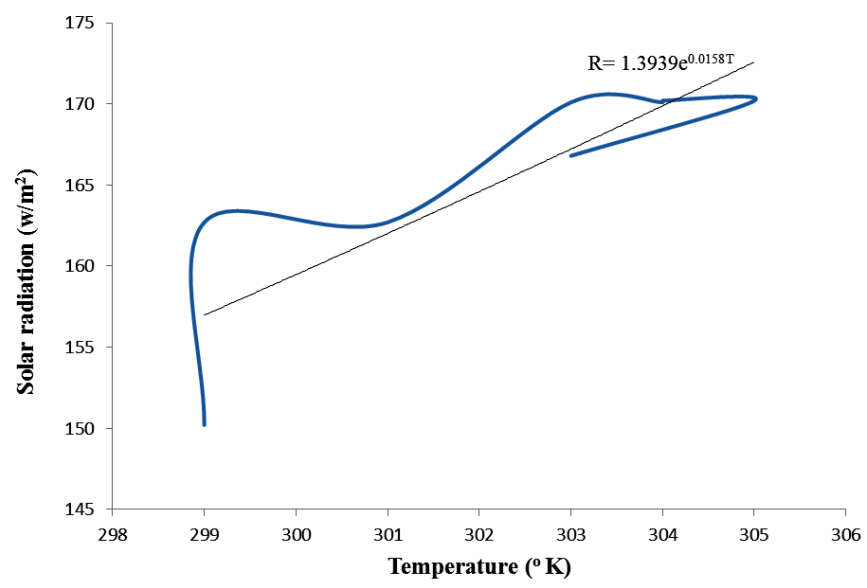

Fig. 3. Showing records for the afternoon on variation in instant solar radiation and instant temperature

$R=0.0182 e^{0.0302 T}$

The corresponding equation as shown in Equation 7 from the graph in Figure 3 is obtained from the software used given as

$R=1.3939 e^{0.0158 T}$

Table 4 and 5 provide the value of Wmea measured, Wcal calculated and the percentage error from the estimated equations for morning and afternoon hours. This is to test for the validity of both morning and afternoon models obtained. As observed from Table 4 and 5, we have a very minimal percentage error and the equation obtained may be taken as valid. From Table 4, it was also observed that there is a normal trend of the temperature values and the solar radiation values from 7:00 am to 11:00 am and also no repetition in the values of both the temperature and the solar radiation measured which gives a high validity of the model estimated from Figure 2.

The graphs in Figure 4 and Figure 5 show the degree of correlation between the measured values gotten from the meteorological centre and the predicted values from the regression analysis. And as evident from curve tracing graphs in Figure 4 and Figure 5 for morning and afternoon hours, respectively, proved the correlation between the measured values and the calculated values of the instant average solar radiation and validity of the estimated model.

From Table 6, it was observed that there is no significant difference in the temperature and solar radiation measured for a particular time throughout the year which gives constant values for both the temperature and the solar radiation. The curve tracing graph for afternoon hours shown in Figure 5 give a greater RMSE value and simultaneously a smaller MBE (a large scatter about the line of perfect measurement). The t-test statistics was used to test for the validity of the estimated models at a confidence level of $95 \%$ where the $\mathrm{H}_{\mathrm{o}}\left(\mu_{m}-\mu_{p}=\right.$ 0 ) since our $t_{\text {cal }}$ is greater than $t_{\text {tab }}$ for both morning and afternoon hours. It is observed in the curve tracing graph for afternoon hours that it is scatter which can be caused due to error in the measurement. Error in measurement of solar radiation values can be arise from early morning dew deposition, directional error, shadowing over the sensor and so caused any errors in the measurement or thermopile sensor not responding to radiation atmosphere. The dome made from one or two layers of ground and polished optical glass or acrylic plastic that shields the thermopile sensor from convection at the period of extremely high temperature because loss of heat due to convection which can reduce the solar radiation measured by the pyranometer and also the desiccants which eliminates air movement and dirt that might affect the measurements. The aim of this work is to propose models for instant solar radiation using instant average temperature of Ogbomoso, in Nigeria and the significance of the models is for the estimation of instant solar radiation at places where measurement are not available to design high performance solar radiation related devices.

Table 4. The morning hours data on percentage error and value of $\mathrm{W}$ measured and calculated from the equation

\begin{tabular}{c|c|c|c}
\hline $\mathrm{W}_{\text {Meas }}$ & $\mathrm{W}_{\text {Cal }}$ & $\mathrm{W}_{\text {meas }}-\mathrm{W}_{\text {cal }}$ & Percentage error \\
\hline 2.153205 & 2.154230 & -0.001025 & -0.04760 \\
2.170848 & 2.167248 & 0.00360 & 0.16583 \\
2.177536 & 2.180265 & -0.002729 & -0.12533 \\
2.203577 & 2.206300 & -0.002723 & -0.12357 \\
2.222196 & 2.219318 & 0.002878 & 0.12951 \\
\hline
\end{tabular}

Table 5. The afternoon hours data on percentage error and value of $\mathrm{W}$ measured and calculated from the equation

\begin{tabular}{c|c|c|c}
\hline $\mathrm{W}_{\text {Meas }}$ & $\mathrm{W}_{\text {Cal }}$ & $\mathrm{W}_{\text {meas }}-\mathrm{W}_{\text {cal }}$ & Percentage error \\
\hline 2.222196 & 2.221545 & 0.000651 & 0.029295 \\
2.23096 & 2.235242 & -0.004282 & -0.191935 \\
2.23096 & 2.228394 & 0.002566 & 0.115018 \\
2.230704 & 2.228394 & 0.00231 & 0.103555 \\
2.230704 & 2.221545 & 0.009159 & 0.410588 \\
2.211388 & 2.207848 & 0.00354 & 0.160080 \\
2.211388 & 2.194152 & 0.017236 & 0.779420 \\
2.17667 & 2.194152 & -0.017482 & -0.803153 \\
\hline
\end{tabular}

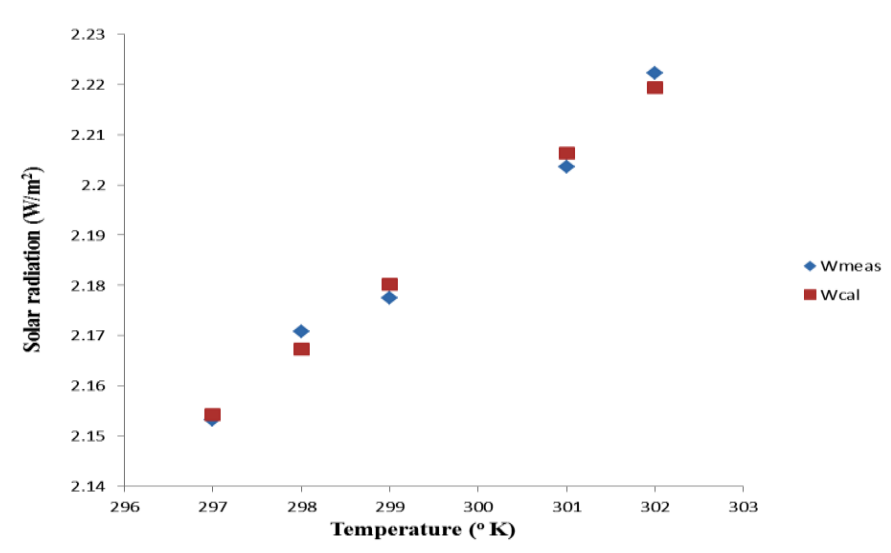

Fig. 4. Curve tracing showing values of $\mathrm{W}_{\mathrm{cal}}$ and $\mathrm{W}_{\mathrm{m}}$ for the morning hours 


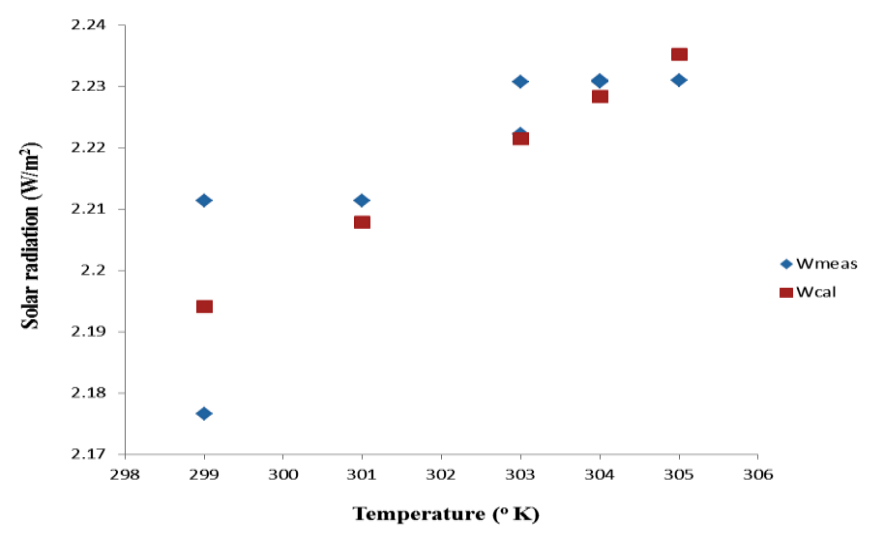

Fig. 5. Curve tracing showing values of $\mathrm{W}_{\mathrm{cal}}$ and $\mathrm{W}_{\mathrm{m}}$ for the afternoon hours

Table 6. The values obtained for statistical indicators used

\begin{tabular}{ccc}
\hline Statistical & Morning Hours & $\begin{array}{c}\text { Afternoon Hours } \\
\text { Indicators }\end{array}$ \\
\hline RMS:00am $-11: 00 \mathrm{am})$ & $(12: 00 \mathrm{pm}-7: 00 \mathrm{pm})$ \\
MBE & 0.001219 & 0.00033769 \\
MPE & -0.0000002 & -0.00171225 \\
\hline
\end{tabular}

\section{Conclusion and Recommendation}

The models estimated in this work for the morning and afternoon hours can be used as another method for measuring the values of solar radiation measure using pyranometer for places of similar climatological and geographical characteristics at which solar records are unavailable. This will solve the problem of insufficient number of meteorological stations in Nigeria which is due to their inability to afford the measuring equipment and lack of maintenance and calibration of the equipment. Instant temperature is easy to measure using digital thermometer which is affordable. But this study is only limited to one year data for a particular geographical location. Instant value included in solar radiation and instant temperature values are essential data for design and efficient functioning of various solar thermal and photovoltaic devices. This will also allow user of the data to track information of solar radiation data in Ogbomoso.

For successive development of such types of empirical relations estimating models on the effects of sky clearness index, cloud cover and wind velocity, relative humidity may also be taken into account in developing the relationship for Ogbomoso area. In this study only one year of area data have been used. Validation using sufficient large amount of data for a longer period of years is required for wider application of the method.

\section{Acknowledgement}

The authors are grateful to NIMET for providing all the necessary data.

\section{References}

[1] N.N. Gana, K. Ral. Jitendra, Musa Momoh, (2014) "Estimation of Global and Diffuse Solar Radiation for Kebbi, North Western Nigeria", International Journal of Scientific \& Engineering Research, Vol. 5, 1: January 2014, 1654-1661.

[2] F. Ahmad, I. Ulfat, (2004) "Empirical Models for the correlation of monthly average daily global solar radiation with hours of sunshine on a horizontal surface at Karachi”, Pakistan. Turk. J. Phys. 28:301-307.

[3] Page, J.K., (1961) "The estimation of monthly mean values of daily total shortwave radiation on vertical and inclined surfaces from sunshine records for latitudes $40^{\circ} \mathrm{N}-40^{\circ} \mathrm{S}$, In proceedings of UN conference on new sources of energy. pp. 378-390

[4] A.N. Maghrabi, (2009), "Parameterization of a simple model to estimate monthly global solar radiation bases on meteorological variables and evaluation of existing solar radiation models for Tabouk, Saudi Arabia", Energy conversion and management. 50: $2754-2760$.

[5] N.L. Mahdi, N.S. Baharn, F.F. Zaki, (1992) "Assessment of solar radiation models for the Gulf Arabian countries", Renew. Energy 2(1):65-71.

[6] L.E. Akpabio, S.O. Udo, S.E. Etuk, (2005) "Modelling Global Solar Radiation for a Tropical Location: Onne, Nigeria”, Turk. J. Phys. 29:63-68.

[7] G.A. Agbo, A. Baba, T.N. Obiekezie, (2010) "Empirical Models for the correlation of monthly average global solar radiation with sunshine hour at Minna", Nig. J. B. Res. 1 (1):41-47.

[8] I.U. Chiemeka, (2008) "Estimation of solar radiation at Uturu, Nigeria”, Inter. J. Phys. Sci. 3 (5):126-130.

[9] G.A. Agbo, (2012) "Estimation of Global Solar Radiation at Onitsha with Regression analysis and artificial Neural Network Models", Res. J. Recent. Sci. 1 (6):1-8.

[10] F.W. Burari, A.S. Sambo, (2001) "Model for the prediction of global solar radiation for Bauchi using Meteorological Data," Nigeria Journal of Renewable Energy, vol. 91, pp $30-33$.

[11] A.M. Al-Salihi, M.M. Kadum, A.J. Mohammed, (2010) "Estimation of global solar radiation on horizontal surface using meteorological measurement for different cities in Iraq," Asian Journal of Scientific Research, vol 3, no 4, pp $240-248$.

[12] E.O. Falayi, J.O. Adepitan, A.B. Rabiu, (2008) "Empirical models for the correlation of global solar radiation with meteorological data for Iseyin, Nigeria," International Journal of Physical Sciences, vol. 3, no 9, pp $210-216$.

[13] P.R. Bavington, (1969) "Data reduction and error analysis for the physical sciences”, McGraw-Hill; New York. 